\title{
ANÁLISIS DE LA EROSIVIDAD DE LA LLUVIA EN ISLA DE MARGARITA (VENEZUELA) A TRAVÉS DE DATOS DE PRECIPITACIÓN HORARIA
}

\author{
Roque Leal Salcedo \\ Instituto de Geografía y Desarrollo Regional \\ Universidad Central de Venezuela
}

\section{RESUMEN}

Este trabajo presenta un análisis de la erosividad de la lluvia a partir de una serie de indicadores que toman como datos los valores de precipitación a escala horaria, todo ello, en el espacio geográfico que corresponde a la Isla de Margarita; espacio insular localizado al Noreste de Venezuela. Estos datos colectados de los registros pluviográficos de las estaciones climáticas: Boca de Pozo y La Guardia durante el periodo de estudio de ocho años (1998-2006). Para este objetivo se realizó una revisión documental de la temática a tratar y posteriormente mediante una caracterización geográfica del área en estudio se desarrolló el cálculo y análisis de índices de erosividad: EI30 De Castro Filho y EI de Lo et al, donde cada dato horario fue considerado un segmento de lluvia, todos con igual duración de 1 hora y como intensidad máxima en 30 minutos se consideró el segmento horario con mayor cantidad de lluvia. De los resultados se logró identificar, explicar y diferenciar las características de los eventos erosivos, además que se condujo a representar su estrecha relación con la intensidad y estacionalidad de las precipitaciones en el periodo de 1998-2006 sobre el área en estudio; logrando además hacer análisis que permitió conocer que sobre el área los eventos erosivos se presentan con mayor frecuencia en los meses lluviosos durante las horas de las 1:00 pm a las 9:00 pm presentándose estos con una precipitación promedio de $23.50 \mathrm{~mm}$ y una intensidad por hora de 16.208 $\mathrm{mm} / \mathrm{hr}$ y se refleja por último, que los índices de Castro Filho y Lo et al guardan cierta correlación con la precipitación anual.

Palabras clave: erosividad hídrica, Isla de Margarita, índices de erosividad, perdida del suelo.

\section{ABSTRACT}

This work presents/displays an analysis of the erosive of rain taking a series from indicators that take like data the values from precipitation on hour scale, all it, in the geographic space that corresponds to the Isla de Margarita; located insular space to the 
Northeast of Venezuela. These collected data of the pluviografic registries of the climatic stations: Boca de Pozo y La Guardia during the period of study of eight years (19982006). In function to this objective a documentary revision of the thematic one was made to treat and later on the basis of a geographic characterization of the area in study it was developed to the calculation and analysis of erosividad; I30 Of Castro Filho and EI of Lo et al, where each hour data was considered a rain segment, all with equal duration of 1 hour and as Maxima intensity in 30 minutes considered the hour segment with greater amount of rain. From the results it was managed to identify, to explain and to differentiate the characteristics from the erosive events, in addition that were conducted to represent their narrow relation with the intensity and estacionalities of precipitations in the period of 1998-2006 on the area in study; managing in addition to make analysis that allowed to know that on the area the erosive events most frequently appear in the rainy months during the hours of 1:00 p.m. to 9:00 p.m. appearing these with a precipitation average of 23,50 $\mathrm{mm}$ and one intensity per 16,208 hour of $\mathrm{mm} / \mathrm{hr}$ and is reflected finally, that the indices of Castro Filho and Lo et al keep certain correlation with the annual rainfall.

Key words: hydric erosive, Venezuela, erosive indices, lost of the ground.

\section{Introducción}

La erosión de suelo es un problema ambiental muy serio que está afectando a la mayoría de los países. Este problema es tan dramático como la reducción de la capa de ozono y el efecto de invernadero, debido a que actualmente están afectando la subsistencia de millones de personas. Como es conocido, la capa de suelo fértil que cubre las tierras agrícolas es de apenas de unos 15 a $20 \mathrm{~cm}$ de espesor y la misma se ve afectada por la erosión causada por el agua o el viento a tasas que exceden su formación.

Otro aspecto a señalar corresponde a que la erosión no es solamente una «enfermedad del suelo», Freile (1962), sino también del paisaje porque incluye a la vegetación, clima, etc. Una vez que la superficie del suelo ha sido removida, el subsuelo puede ser más vulnerable a la erosión, debido a la falta de materia orgánica que hace que la cubierta vegetal protectora se establezca con dificultad y si el subsuelo no es de textura arcillosa entonces hay menos agentes cementantes para mantener las partículas juntas.

En referencia a lo comentado, a nivel latinoamericano se halla el documento titulado Soil erosion survey of Latin America (1954), desarrollado por la Fundación de Conservación y la Organización de las Naciones Unidas para la Agricultura y la Alimentación que expresa como uno de sus resultados, los datos que se resumen en el cuadro 1, donde se indica la distribución del grado de severidad de erosión en los países de Argentina, Bolivia, Brasil, Chile y Paraguay.

Como se indica en el cuadro 1, para el año 1954, casi la mitad de las tierras tenían bosques primarios y en relación a la erosión del suelo, el fenómeno afectó a todos los cinco países para los grados $\mathrm{A}, \mathrm{A} / \mathrm{B}$ y $\mathrm{B}$, en grado B/C la erosión afectó algunas áreas de Argentina, Brasil y Chile y finalmente se detectó erosión severa en unos 1600 km² en Brasil.

De lo expuesto, se aprecia que hace medio siglo, la erosión dentro estos países alcanzó un total de $13.432 .688 \mathrm{~km}^{2}$ de tierras afectadas por esta consecuencia y es allí donde inicia el motivo del presente estudio, en el cual se dedicará, sin menoscabo de agotar la discusión en cuanto a la temática, el estudio de la erosión particularmente en lo referido al fenómeno de erosividad de la lluvia tomando como área en estudio la Isla de Margarita, territorio correspondiente al estado Nueva Esparta de la República de Venezuela. (Figura 1) 


\section{Cuadro 1}

EVALUACIÓN DEL GRADO DE LA SEVERIDAD DO LA EROSIÓN EN 1954 EN ARGENTINA, BOLIVIA, BRASIL, CHILE Y PARAGUAY (expresado en $\mathrm{km}^{2}$ )

\begin{tabular}{|c|c|c|c|c|c|c|c|}
\hline \multicolumn{2}{|r|}{ Grados de Erosión } & Argentina & Bolivia & Brasil & Chile & Paraguay & Total \\
\hline A & $\begin{array}{l}\text { Muy poca o } \\
\text { ninguna erosión }\end{array}$ & 345794 & 398615 & 651484 & 68118 & 95717 & 2559729 \\
\hline $\mathrm{A} / \mathrm{B}$ & $\begin{array}{l}\text { Predomina poca } \\
\text { erosión } 10 \% \text { al } \\
25 \% \text { de las tierras } \\
\text { están desgastadas } \\
\text { moderadamente o } \\
\text { en exceso }\end{array}$ & 1430251 & 68944 & 788168 & 85609 & 4869 & 2377841 \\
\hline B & Erosión moderada & 422519 & 167889 & 666986 & 8703 & 11176 & 1267275 \\
\hline $\mathrm{B} / \mathrm{C}$ & $\begin{array}{l}\text { Erosión moderada: } \\
10 \% \text { al } 25 \% \text { de las } \\
\text { tierras desgastadas }\end{array}$ & 107728 & 0 & 614025 & 32985 & 0 & 754739 \\
\hline $\mathrm{C}$ & Erosión severa & 0 & 0 & 1655 & 0 & 0 & 1655 \\
\hline I & $\begin{array}{l}\text { Tierras con capa } \\
\text { vegetal y virgen }\end{array}$ & 466866 & 450133 & 4746018 & 518041 & 288330 & 6469390 \\
\hline & Otros & 1355 & 701 & & & & 2056 \\
\hline & Total & 2774514 & 1086283 & 8458338 & 713458 & 400094 & 13432688 \\
\hline
\end{tabular}

Fuente: Soil erosion survey of Latin America (1954)
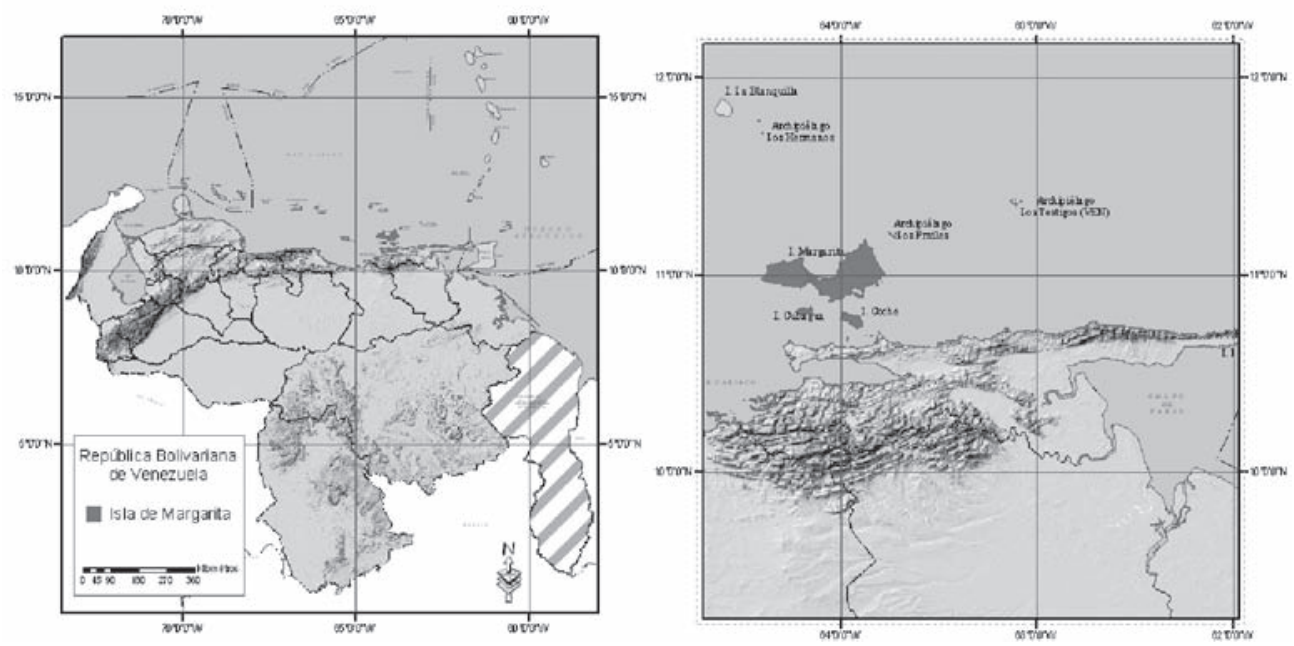

FiguRA 1. Ubicación relativa del área en estudio. 


\section{Materiales y métodos}

En concordancia con las limitaciones propias de la investigación, originada por la necesidad de analizar los eventos de lluvia erosiva directamente sobre la banda pluviográfica, indujo a tomar como alternativa para determinar la erosividad de la lluvia, la información pluviométrica obtenida de los pluviogramas y recopilada en bases de datos, de las estaciones Boca de Pozo y La Guardia, ubicadas dentro del área en estudio. (figura 3)

El organismo encargado de proveer la información fue la Dirección de Hidrología y Meteorología del Ministerio del Ambiente y de los Recursos Naturales Renovables (DHMMARNR), que además coordina el funcionamiento de las estaciones meteorológicas suscritas a su red y la preparación de los observadores meteorológicos. La mínima resolución temporal de la información pluviométrica es horaria y, a partir de esta, se generan los datos mensuales y anuales para todas las estaciones del país; bajo esta condición, se decidió basar la investigación en la aplicabilidad de los datos horarios.

Los índices de erosividad empleados fueron el índice EI30 y Lo et al. El índice EI30, desarrollado en los Estados Unidos por Wischmeier y Smith (1958) y que desde sus inicios ha sido aplicado ampliamente a nivel mundial dado la relación significativa que demostraron sus autores con las pérdidas de suelo.

Para su calculó en el presente estudio se consideró en índice de De Castro Filho (1982), con su índice EI30 modificado a las condiciones de áreas tropicales:

$\mathrm{EI} 30=28,814+(10,800+7,896 \log \mathrm{I} 30) \times \mathrm{P} \times \mathrm{I} 30 \times 10-3$

EI30: índice de erosividad en ton- $\mathrm{m} . \mathrm{mm} / \mathrm{ha} . \mathrm{h}$

$\mathrm{I} 30$ = intensidad máxima en 30 minutos en $\mathrm{mm} / \mathrm{h}$

$\mathrm{P}=$ lluvia en $\mathrm{mm}$

Por su parte igualmente se trabajó con el índice Lo et al (1985) en la que corresponde a un cálculo más exacto y simplificado del I30 a través de la ecuación:

$\mathrm{EI}=38,46+3,48 \mathrm{P}$

Donde:

$\mathrm{EI}=$ erosividad de la lluvia en $100 \mathrm{Nw} / \mathrm{h}$

$\mathrm{P}=$ lluvia media anual en $\mathrm{cm}$

Finalmente, estos índices fueron calculados a partir de los datos registrados y se llegaron a conclusiones y análisis que dieron cumplimiento a los objetivos propuestos en la investigación.

\section{Marco teórico}

\section{La erosividad de la lluvia}

Definido el objeto de estudio de la investigación, se hace necesario tener una conceptualización de lo que refiere el termino erosividad de la lluvia y sus factores para luego abarcar lo referido a la caracterización geográfica del área en estudio. En atención al concepto erosividad de la lluvia, primeramente se tiene que el agua a través del fenómeno de la precipitación inicia su acción erosiva inmediatamente luego que las gotas golpean el suelo descubierto.

Este proceso de martilleo de la lluvia había sido despreciado durante muchos años hasta que se realizaron diferentes ensayos comparativos y se logró observar directamente el impacto particular de las gotas y la desagregación del suelo a causa de este fenómeno. Ciertamente las gotas provocan un desplazamiento marcado de las partículas durante el salpicamiento (Figura 2). Por ejemplo, «una gota de $5 \mathrm{~mm}$ puede proyectar las partículas 
de $4 \mathrm{~mm}$ hasta una distancia de $20 \mathrm{~cm}$, y las partículas mas finas hasta 1,5 m» Dohrenheld, (1977); Cooke and Doornkamp, (1974). Este proceso logra un impacto erosivo (erosión por salpicamiento) notable en tierras inclinadas, debido al transporte asimétrico y dirigido hacia las partes inferiores en función del ángulo del terreno mismo, así como de las fuerzas de la gravedad. (figura 2)

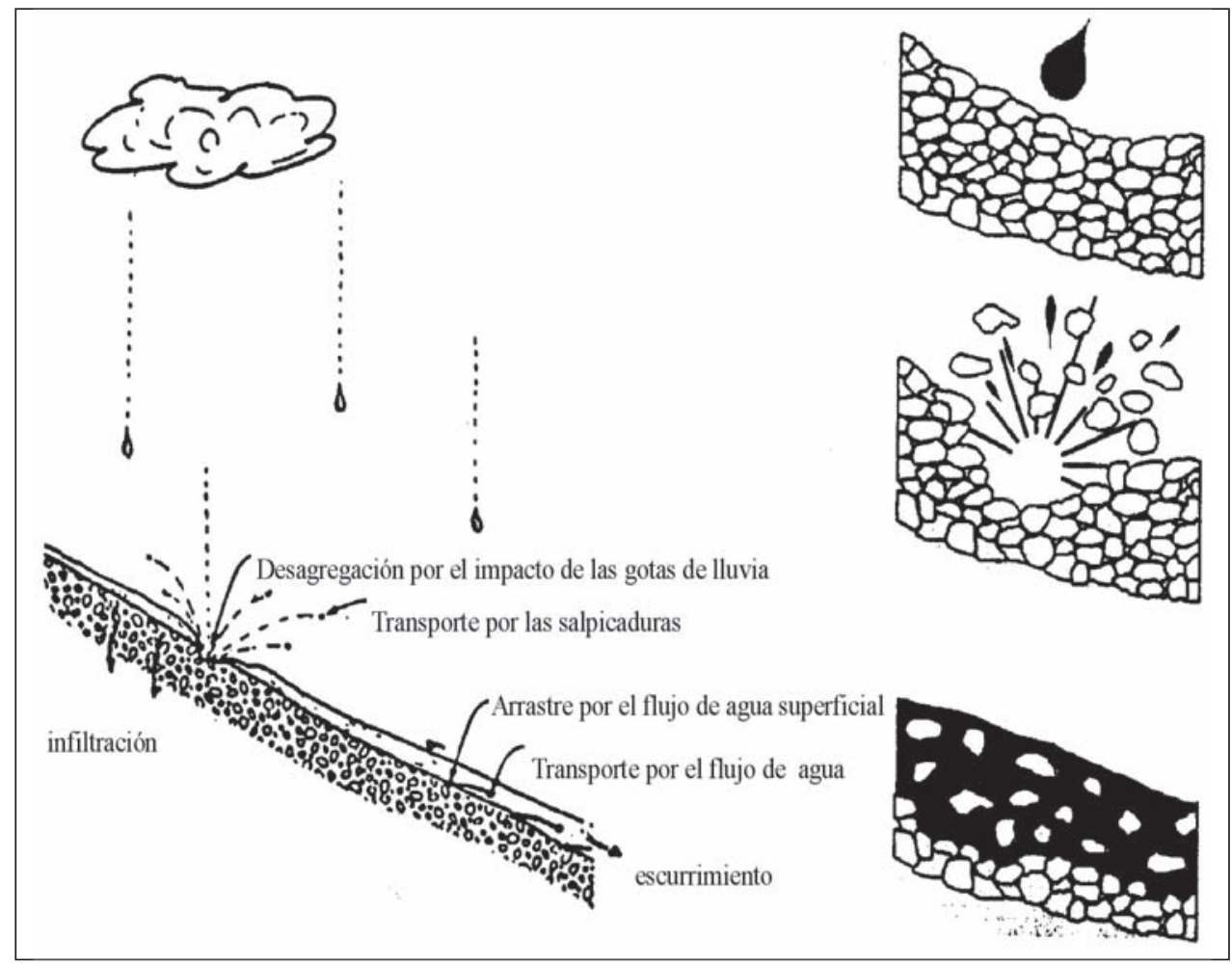

Figura 2: procesos de Erosión Hídrica, adaptado de Julien y Frenette, (1986).

\section{Resultados}

\subsection{Caracterización físico geográfica del área de estudio: Isla de Margarita}

\subsubsection{Localización}

El Estado Nueva Esparta está formado por las islas de Margarita, Coche y Cubagua y se localiza en el mar Caribe, al nororiente de Venezuela, frente a las costas del estado Sucre. Sus coordenadas geográficas son las siguientes: $10^{\circ} 51^{\prime} 54^{\prime \prime} ; 11^{\circ} 10^{\prime} 36^{\prime \prime}$ de latitud Norte y 6346' 36"; 64 $25^{\circ} 42^{\prime}$ " de longitud Oeste. Tiene por límites las aguas del Mar Caribe. (Figura 3) 


\subsubsection{Clima}

Como región insular de proporciones relativamente pequeñas, el estado Nueva Esparta tiene un clima altamente afectado por la altura al nivel del mar, las condiciones oceánicas, los vientos alisios y los centros de presión. No obstante, la presencia de dos bloques montañosos actúa como factor de variabilidad. Según datos de las estaciones climáticas seleccionadas, la temperatura media anual es alta en casi todo el estado (entre $26^{\circ}$ y $28^{\circ} \mathrm{C}$ ), con escasa variación diaria y con máximas de mayo a septiembre y mínimas de diciembre a enero. La insolación es elevada y la evapotranspiración potencial oscila entre $1.600 \mathrm{y}$ $1.800 \mathrm{~mm}$. Ello determina un clima de tipo semiárido en casi todo el estado.

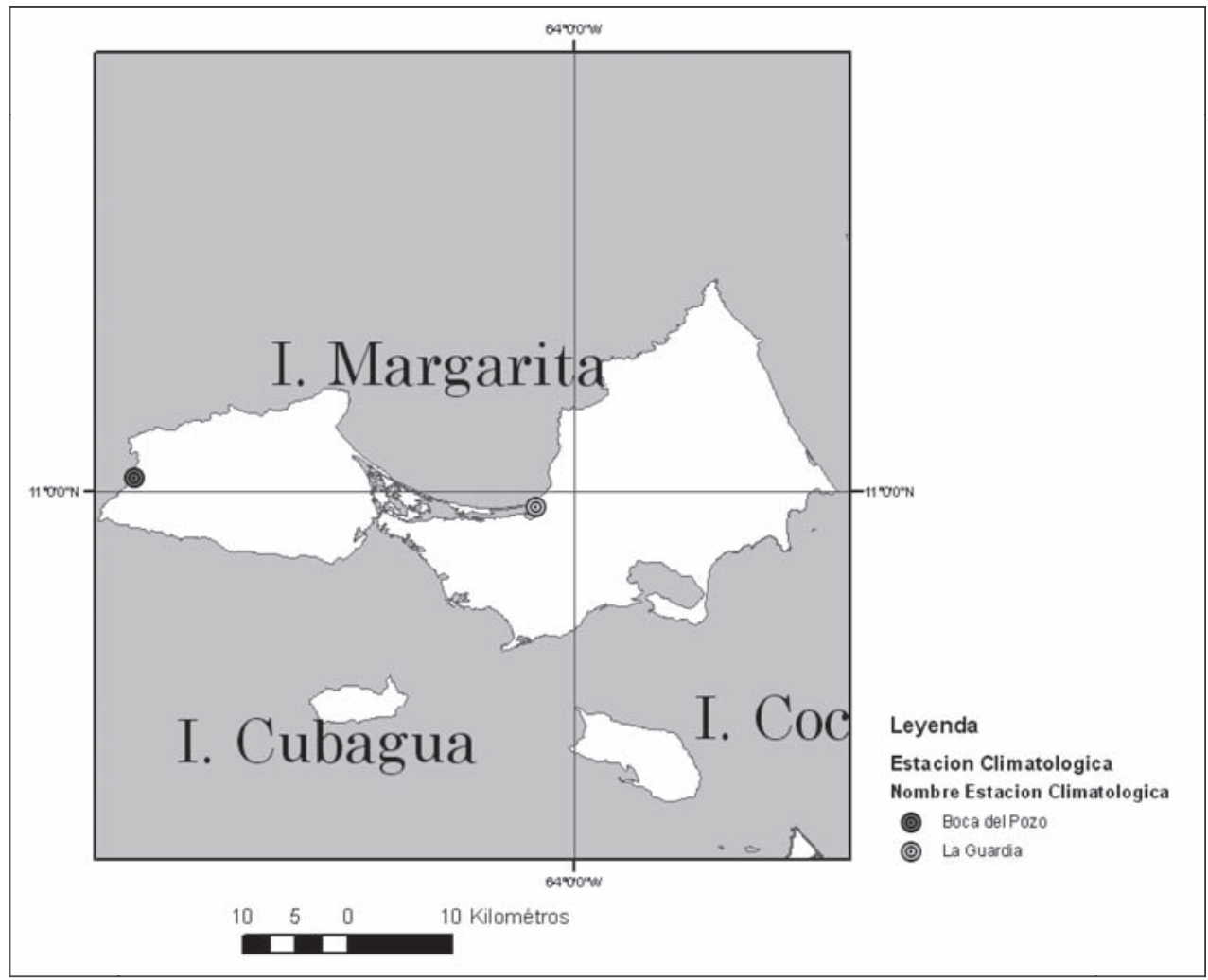

FIGURA 3: Estaciones climáticas en estudio.

El régimen de precipitación se caracteriza por dos períodos lluviosos (de junio a agosto y de diciembre a febrero) y dos secos (marzo a mayo y septiembre a noviembre), pero el balance hídrico es deficitario durante todo el año. La humedad relativa media es de 70 a 80 por ciento en la mayor parte de la isla, excepto en las montañas. La zona de mayor precipitación es el bloque montañoso oriental, aunque con grandes variaciones, pues los registros oscilan entre 400 y $1.100 \mathrm{~mm}$ anuales. En la península de Macanao, a pesar de las montañas, la precipitación es menor debido a la acción de los vientos alisios (entre 300 y $500 \mathrm{~mm}$ anuales). La precipitación decrece con la altura. 


\subsubsection{Vegetación}

En la isla de Margarita los efectos climáticos y/o edáficos han producido una mezcla de zonas de vida, con variados ecosistemas que comprenden desde la maleza desértica tropical, en las zonas bajas y secas, hasta el monte espinoso y el bosque seco tropical en zonas de mayor altura. En el cerro Copey se encuentra el bosque húmedo premontano y en las zonas pantanosas y salinas abundan los manglares. Las especies más representativas son olivos, dividive y pardillo, alrededor de los cerros Copey, Matasiete y Guaraguao. El bosque muy seco se encuentra en áreas de vegetación muy intervenida. Las principales especies son: cují, guatacare, guamache, cardón, dividive y olivo. Los espinares y las malezas desérticas, formaciones dominantes del estado, ocupan las llanuras costeras. Sus principales especies son abrojo, cují, yaque, orégano, tuna, cardón, dividive, guamache y otras. Las concentraciones de manglares se localizan en La Restinga, Las Marites y otras zonas de agua costaneras. Las especies más importantes son el mangle colorado, botoncillo y el mangle negro. (Figura 4)

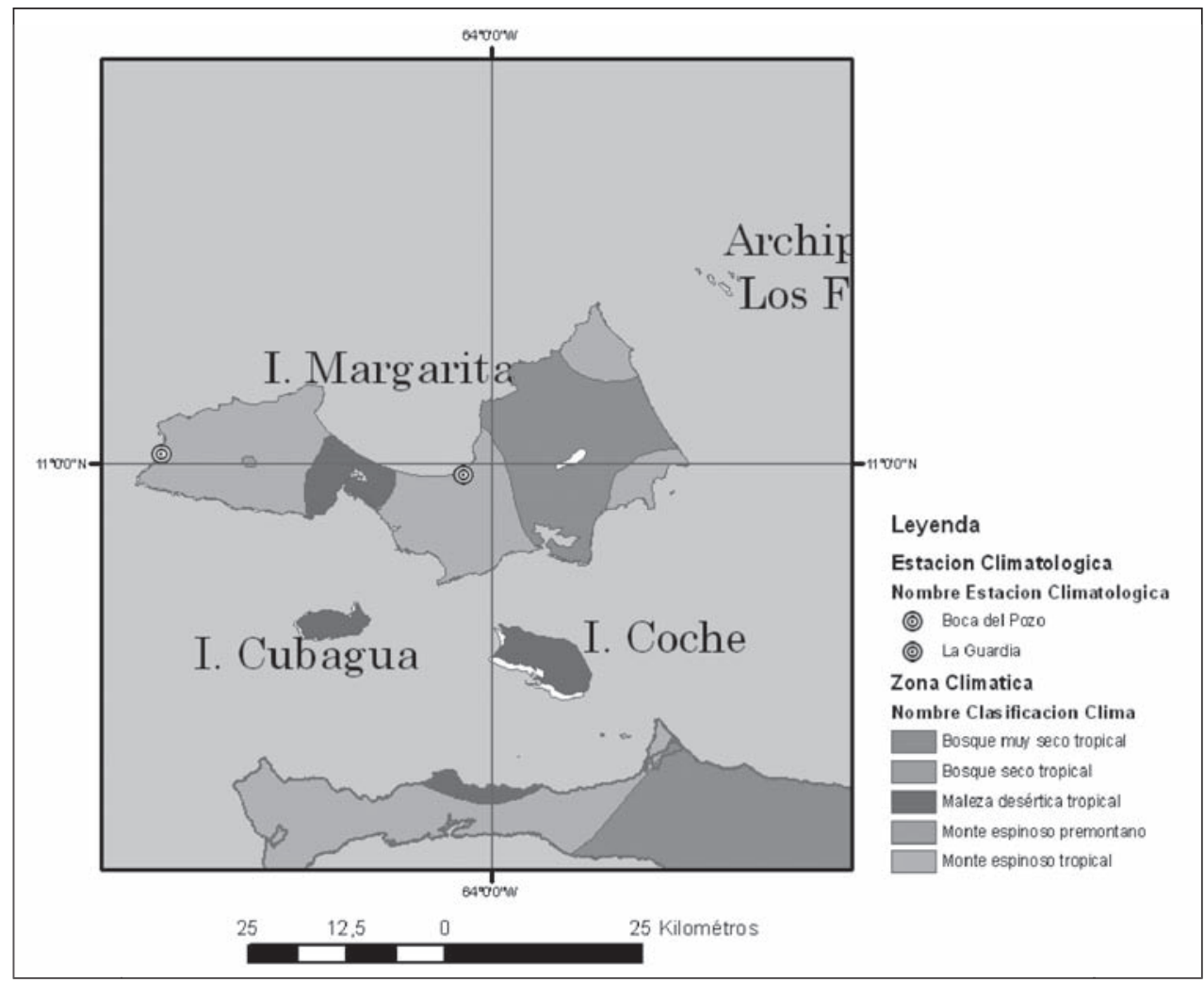

FIGURA 4: tipo de vegetación según zona climática. 


\subsubsection{Geología}

Los sectores de montaña, basamento geológico del Estado Nueva Esparta, están compuestos por formaciones igneo-metamórficas de la era mesozoica. La zona costera está constituida por formaciones sedimentarias mientras que las terrazas marinas son formaciones aluvionales y depósitos lagunares.

\subsubsection{Suelos}

Los suelos del Estado Nueva Esparta son el resultado de procesos de adición, pérdida o transposición de materiales en zonas áridas y de escasa vegetación. Son suelos delgados y pocos desarrollados, sujetos a intensos procesos erosivos acelerados por el sobrepastoreo, las oscilaciones del nivel del mar y la deforestación realizada para el aprovechamiento agrícola. Los suelos de los valles, las tierras de mejor calidad, son bien desarrollados, tienen capa orgánica, están protegidos de la acción erosiva del viento y se encuentran cubiertos de vegetación, pero sólo ocupan una pequeña proporción del estado. En las zonas de piedemonte, los conos de deyección y materiales coluviales dan lugar a suelos muy pedregosos. Las islas de Coche y Cubagua presentan suelos con salinidad y con una fuerte erosión resultante de la acción de los vientos, lo cual le confiere a su capa superficial un carácter pedregoso.

\subsubsection{Relieve}

La isla de Margarita está constituida por dos secciones que originalmente fueron dos islas y que se encuentran unidas actualmente por una restinga ó cordón arenoso. Tiene dos paisajes dominantes: las zonas montañosas y las zonas planas costeras. En la sección oriental se destacan el macizo El Copey, cuyas mayores alturas son los cerros de Choaima (810 m) y Grande o San Juan (910 m), la mayor de la isla, y la fila integrada por los cerros de Matasiete $(670 \mathrm{~m})$ y Guayamurí $(480 \mathrm{~m})$.

Los principales valles de este bloque son San Juan, Pedro González, La Asunción y el valle del Espíritu Santo. En la sección occidental o península de Macanao, el núcleo montañoso está formado por una fila de cerros cuyas principales alturas son el cerro Macanao (750 m), Los Cedros (745 m), cerro Risco Blanco (680 m) y Guaraguao (660 m). Alrededor de estos conjuntos montañosos domina la llanura. Gran parte de la isla está formada por llanuras costeras, como la de Juan Griego, Puerto Fermín-El Agua y la más importante, al suroeste, desde la laguna de Las Marites hasta Bahía de Mangle y desde La Restinga hasta el mar, en donde los únicos accidentes son el cerro Aguaverde (100 m), las Tetas de María Guevara (100 m) y la serranía de Banco Largo. El relieve de las islas de Coche y Cubagua está representado por tierras bajas costeras con elevaciones inferiores a los $70 \mathrm{~m}$.

\subsubsection{Hidrografía}

El agua es un recurso muy escaso en el Estado Nueva Esparta pues los períodos de lluvia son cortos y las precipitaciones reducidas. No existen ríos propiamente dichos sino cursos de agua que se forman durante las épocas de lluvia y permanecen secos durante casi todo el año. El estado depende del suministro de agua de tierra firme, el cual se efectúa mediante un acueducto submarino.

En virtud de los elementos reseñados se puede dar inicio al análisis del elemento erosividad hídrica tomando como referencia los datos de precipitación provenientes de las estaciones climáticas seleccionadas. 


\subsection{Análisis de la erosividad en las estaciones de estudio}

\subsubsection{Estación Boca de Pozo. Serial 0791}

La estación Boca de Pozo, perteneciente a la red de estaciones meteorológicas del Ministerio del Ambiente y Recursos Naturales, se encuentra instalada en el extremo Oeste de la Isla de Margarita, sobre las coordenadas Latitud Norte: $11^{\circ} 0^{\prime} 04^{\prime \prime}$ y Longitud Este $64^{\circ} 22^{\prime} 36^{\prime \prime}$ (ver figura 4), sobre a lo que corresponde a una amplia planicie de origen sedimentario, donde la acción fluvio-marina ha jugado un papel importante en el proceso de deposición de los sedimentos acarreados desde los sectores montañosos de la Serranía de Macanao, al igual del tipo de vegetación predominante, la cual de acuerdo a su tonalidad y textura, es propia de Bosque Seco Tropical. El registro que se utilizó en el análisis de la erosividad, comprende el período de enero de 1998 a enero de 2006 y la información se basó en los datos horarios de la correspondiente estación, cuya información pluviométrica se halla resumida en el cuadro 2.

El comportamiento espacio-temporal de la precipitación de la precipitación sobre esta estación de acuerdo al cuadro 1, se ve determinado por tres factores relacionados con su génesis. En primer lugar, por las lluvias originadas por el avance hacia el Norte y posterior retorno, de la Zona de Convergencia Intertropical (ZCIT) cuya acción se puede observar generalmente sobre los meses de abril a noviembre. En segundo lugar, se tienen las precipitaciones debidas a situaciones que conjugan inestabilidad atmosférica, factores orográficos y dirección del viento, que pueden ocurrir en cualquier momento del año; en este caso se encuentran afectadas especialmente aquellas zonas con laderas orientadas en dirección NE-SW, N-S o NW-SE, es decir, aquellas que interceptan el paso de los vientos alisios provenientes del Este y Noreste, los cuales soplan constantemente sobre el país, aunque con mayor frecuencia y velocidad durante la temporada seca. En tercer lugar, a la ocurrencia de precipitaciones asociadas a situaciones meteorológicas «Norte» (vaguadas en la altura y restos de frentes fríos), que generalmente se manifiestan en diciembre y febrero sobre todo en estas áreas costeras.

De acuerdo al cuadro 2, la precipitación media anual varia de $893.4 \mathrm{~mm}$ a $117.1 \mathrm{~mm}$ con una media de $379.6 \mathrm{~mm}$ y una desviación estándar de $216.4 \mathrm{~mm}$ siendo los meses de agosto y septiembre, lo más lluviosos, con precipitaciones que superan los $60 \mathrm{~mm}$, por lo que la ocurrencia de los fenómenos asociados a la erosividad deben ser mayores sobre estos meses a diferencia de los meses de junio, julio, octubre, noviembre y diciembre los cuales poseen un comportamiento transicional donde las precipitaciones se encuentran entre los $30 \mathrm{~mm}$ y $60 \mathrm{~mm}$, también tenemos como meses secos los meses de enero a mayo, con precipitaciones menores a los $30 \mathrm{~mm}$; este tipo de condiciones permite diferenciar dos temporadas bien definidas a lo largo de todo el año: una seca y de gran variabilidad, conformada por los meses de enero a mayo, y otra temporada transicional a lluviosa que comprende los meses de junio a diciembre, presentándose una menor variabilidad. La proporción de lluvia aportada en los meses secos alcanza solo el $8.14 \%$ con $31.3 \mathrm{~mm}$ de lluvia, mientras que en los meses lluviosos el porcentaje alcanza el valor de $91.85 \%$ con $353.2 \mathrm{~mm}$, y que coincide con los meses de mayor incidencia de eventos erosivos. El mes más seco de año es abril, con una precipitación medio de $0.99 \mathrm{~mm}$ a diferencia del mes más lluvioso de agosto con $95.2 \mathrm{~mm}$ de precipitación media, seguido de septiembre y julio con $65.8 \mathrm{~mm}$ y $55.7 \mathrm{~mm}$ de lluvia respectivamente.

En lo que corresponde a la distribución de las lluvias a lo largo del día, se indica en el gráfico 1, que las mayores precipitaciones las hallamos desde las 12:00 pm hasta las 9:00 pm, presentando los valores más altos en la hora de las 7:00 pm, siendo estas horas, la de 


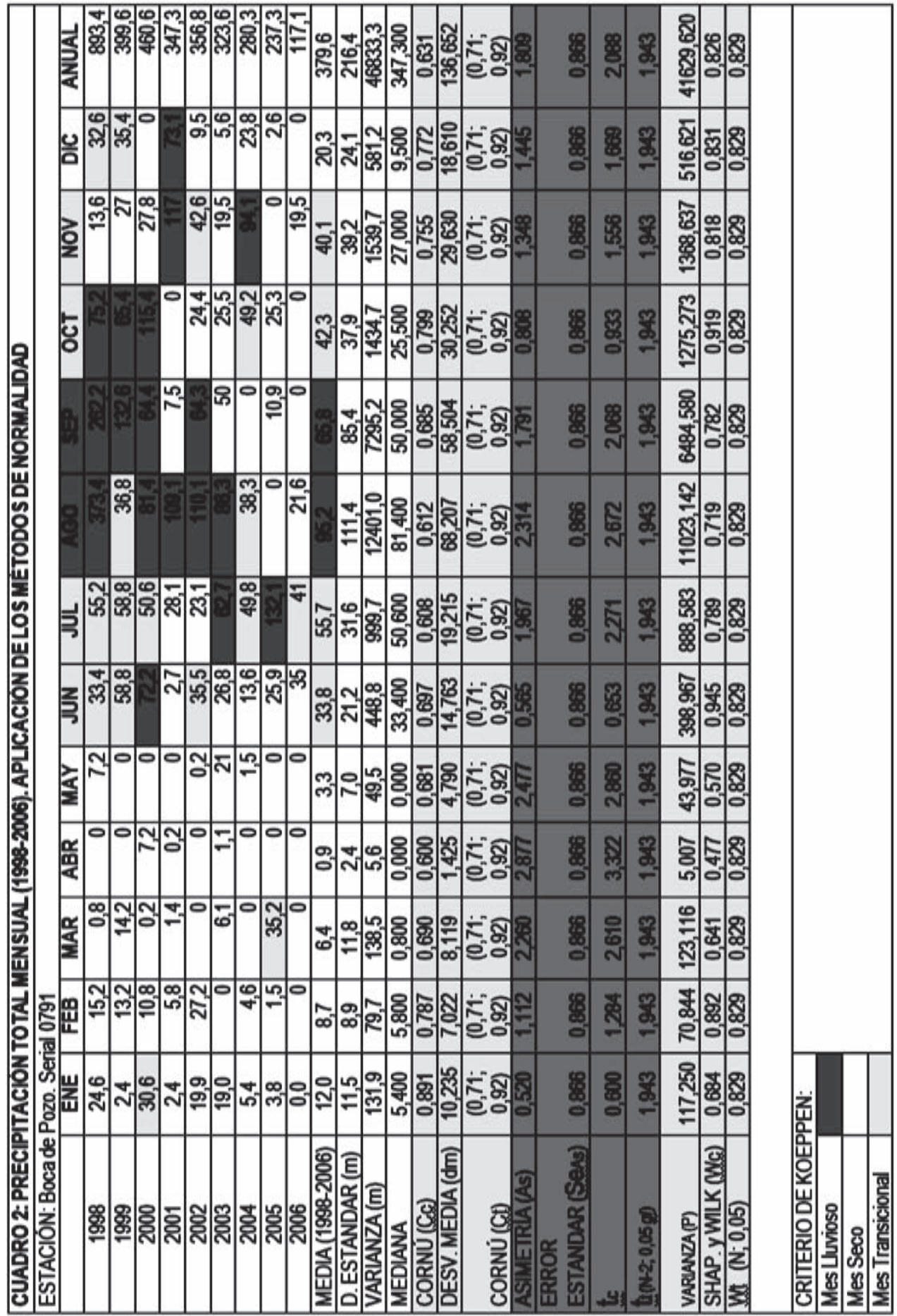


mayor ocurrencia de eventos erosivos sobre los meses de julio a septiembre (ver cuadro 3 ), estos eventos se presentan con una precipitación media de $22.83 \mathrm{~mm}$ con una desviación estándar de $14.05 \mathrm{~mm}$ y con una intensidad por hora promedio de $16 \mathrm{~mm} / \mathrm{hr}$ con una desviación estándar de $9.04 \mathrm{~mm} / \mathrm{hr}$.

El análisis de la precipitación horaria a escala anual (Cuadro 4), indica que es el año de 1998 donde se presenta la mayor incidencia de eventos, siendo el de menor incidencia el año de 2006, pero tal aseveración pudiera originarse debido a la falta de consistencia de los datos, reportándose para ese año el mayor porcentaje de datos faltantes y/o englobados (23.13\%), por otra parte, los valores más altos de precipitaciones coinciden con los índices EI30 De Castro Filho más altos y con los meses más lluviosos, presentándose sobre las horas más probables las cuales parten desde las 12:00 pm hasta las 9:00 pm. Siguiendo con este índice, tenemos que, el evento más agresivo fue el ocurrido el 26 de julio de 2005 reportándose un valor de 163.3 ton.m.mm/ha.hr, sin embargo, el valor promedio de este índice se encuentra en los 33.45 ton.m.mm/ha.hr (Gráfico 2).

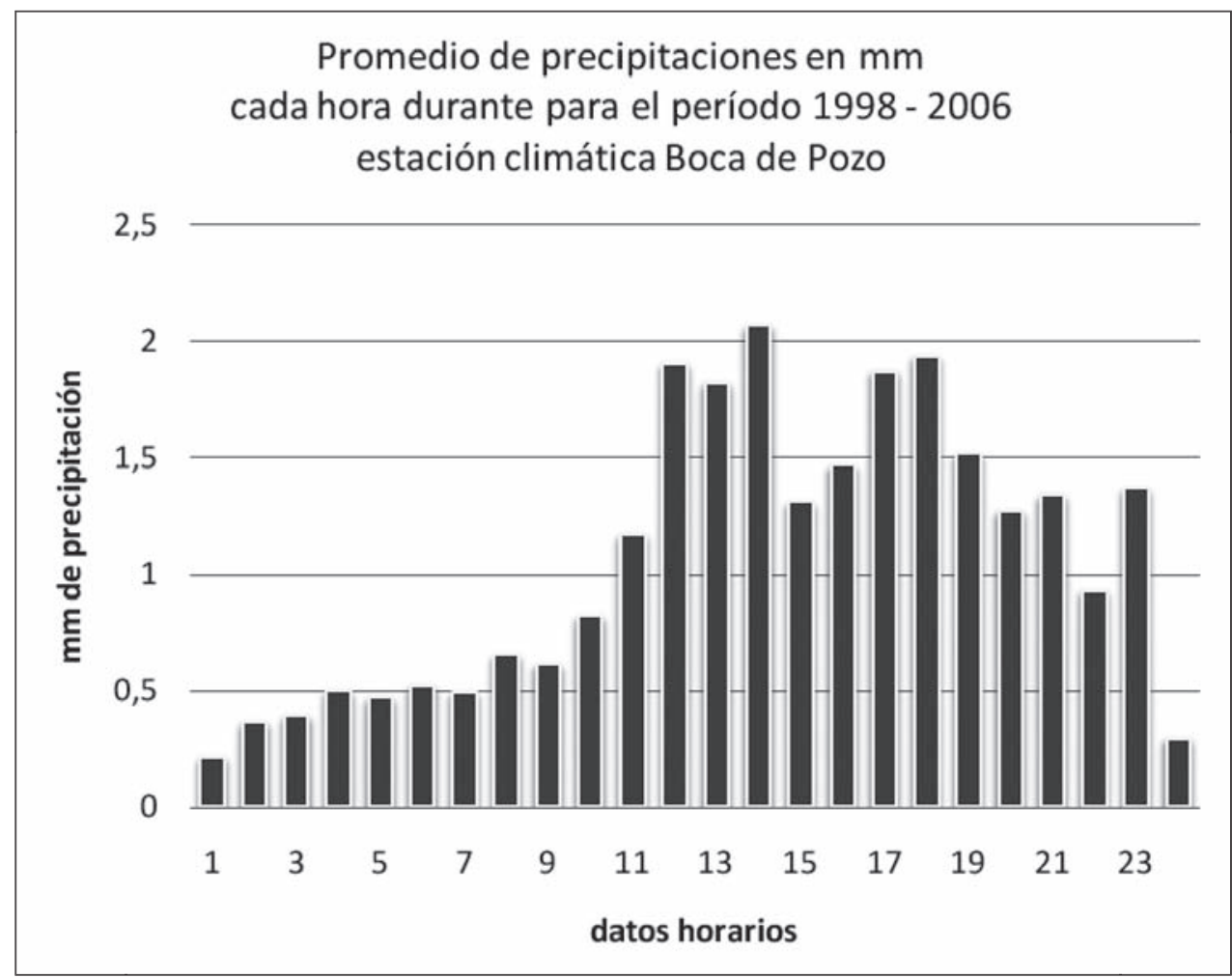

GRÁFICo 1: promedio de precipitación horaria, periodo 1998-2006. 


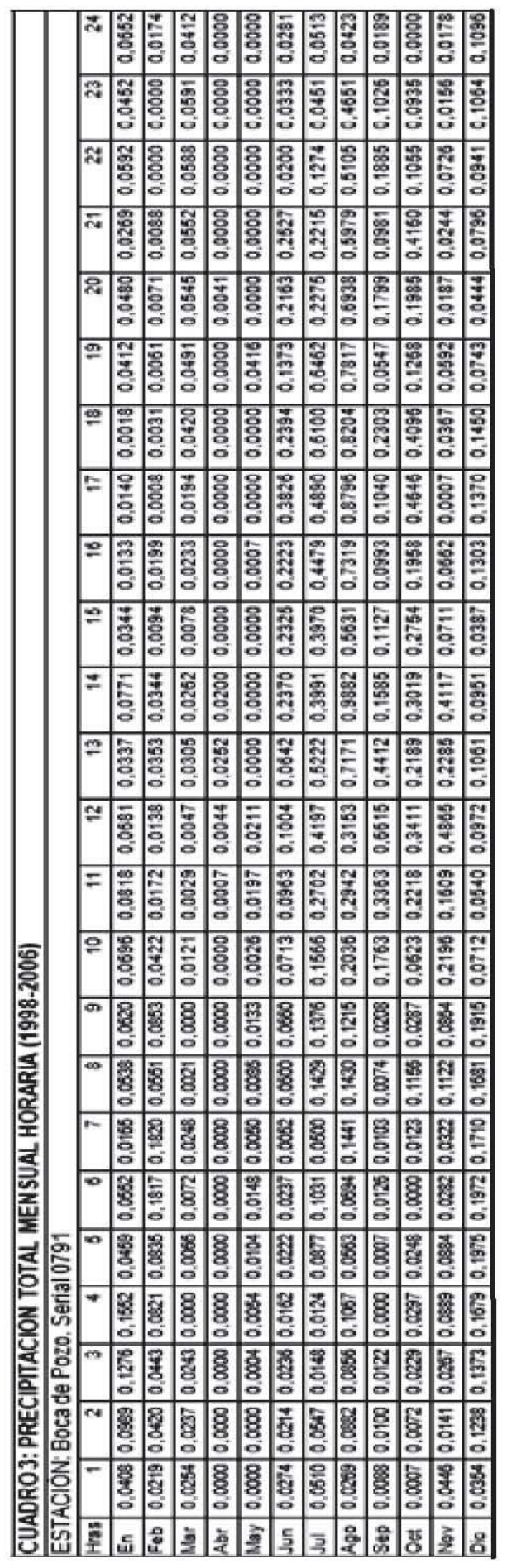

\begin{tabular}{|c|c|c|c|c|c|c|c|c|c|c|c|}
\hline & 吉 & \begin{tabular}{|l|}
8 \\
8
\end{tabular} & $\begin{array}{l}\text { 영 } \\
\end{array}$ & \begin{tabular}{|l|} 
总 \\
:
\end{tabular} & & 煦 & \begin{tabular}{|l|} 
쳥 \\
\end{tabular} & \begin{tabular}{|l|} 
홍 \\
\\
\end{tabular} & \begin{tabular}{l|}
$g$ \\
0 \\
0
\end{tabular} & \begin{tabular}{|l|}
$\delta$ \\
$\delta$ \\
\end{tabular} & $\begin{array}{l}\text { 苦 } \\
0\end{array}$ \\
\hline & $\mathbb{N}$ & \begin{tabular}{|l|}
5 \\
8 \\
8 \\
\end{tabular} & 范 & 영 & 응 & 영 & 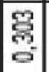 & 흥 & 옿 & $\begin{array}{l}8 \\
8 \\
0\end{array}$ & 䓵 \\
\hline & \& & 急 & $\frac{3}{6}$ & $\frac{\pi}{5}$ & 总 & 웅 & \begin{tabular}{|c|} 
\\
\\
\end{tabular} & 영 & 훙 & 壱 & s \\
\hline & $\bar{N}$ & & 兽 & 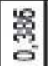 & \begin{tabular}{|l|} 
娄 \\
0
\end{tabular} & 용 & 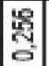 & $\begin{array}{l}8 \\
8 \\
\end{array}$ & 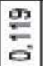 & 总 & 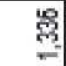 \\
\hline & ק & 疍 & 옇 & $\begin{array}{l}\text { 웅 } \\
\end{array}$ & 氨 & $\frac{0}{6}$ & \begin{tabular}{|l}
$E$ \\
s.
\end{tabular} & 量 & $\frac{0}{0}$ & 要 & 롱 \\
\hline & \% & \begin{tabular}{|l|}
\multirow{2}{*}{} \\
\\
0
\end{tabular} & 홍 & $\begin{array}{l}\text { 兽 } \\
\end{array}$ & \begin{tabular}{|l|}
$\overline{5}$ \\
\\
\end{tabular} & 영 & 등 & \begin{tabular}{|l|}
8 \\
\end{tabular} & 동 & 宮 & 문 \\
\hline & 의 & $\begin{array}{l}\mathrm{g} \\
\mathrm{s} \\
\mathrm{d}\end{array}$ & $\begin{array}{l}\text { 哭 } \\
\text { 영 }\end{array}$ & $\begin{array}{l}\text { \% } \\
8 \\
8\end{array}$ & $\frac{3}{0}$ & $\begin{array}{l}\frac{9}{8} \\
\mathrm{~d}\end{array}$ & $\begin{array}{l}\frac{m}{7} \\
0\end{array}$ & 骂 & 商 & 훙 & 夻 \\
\hline & $=$ & & 管 & \begin{tabular}{|l|}
$\frac{9}{5}$ \\
5 \\
\end{tabular} & 웅 & 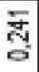 & 点 & 产 & 엻 & 颉 & 兽 \\
\hline & $\%$ & $\begin{array}{l}\bar{F} \\
\text { 案 }\end{array}$ & ㅎㅎㅇ & 空 & \begin{tabular}{|c|} 
䎏 \\
-
\end{tabular} & $\frac{6}{6}$ & $\begin{array}{l}0 \\
0 \\
0\end{array}$ & 㔛 & \begin{tabular}{|l}
5 \\
$\frac{5}{6}$ \\
\end{tabular} & $\frac{8}{6}$ & 洺 \\
\hline & 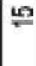 & & $\frac{5}{0}$ & $\begin{array}{c}\text { 荵 } \\
\text { s. }\end{array}$ & $\begin{array}{l}0 \\
0 \\
0 \\
0\end{array}$ & 畹 & $\begin{array}{l}\frac{9}{\mathrm{~g}} \\
\\
\end{array}$ & 営 & E & $\frac{8}{0}$ & 占- \\
\hline & \pm & 产 & $\frac{9}{0}$ & $\begin{array}{l}\text { 昫 } \\
0 \\
0\end{array}$ & 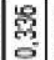 & $\frac{9}{\frac{9}{2}}$ & $\begin{array}{l}E \\
0 \\
0\end{array}$ & 胥 & $\stackrel{\text { g. }}{\stackrel{2}{0}}$ & 总 & 용 \\
\hline & ? & 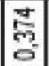 & $\begin{array}{l}\text { 울 } \\
\text { 영 }\end{array}$ & 듬 & \begin{tabular}{|l|} 
\\
\\
0
\end{tabular} & $\frac{N}{0}$ & 䍃 & 정 & \begin{tabular}{|l|}
$\frac{0}{0}$ \\
$\vdots$ \\
0
\end{tabular} & $\frac{8}{6}$ & 동- \\
\hline & $\cong$ & & 䩶 & 总 & 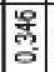 & $\overline{\bar{y}}$ & \begin{tabular}{|l|} 
\\
\\
0
\end{tabular} & $\begin{array}{l}E \\
\end{array}$ & 웅 & 慦 & 8. \\
\hline & $=$ & $\begin{array}{l} \\
\text { 嵒 } \\
\end{array}$ & 量 & $\begin{array}{l}8 \\
\frac{8}{5} \\
\end{array}$ & 喜 & 영 & 总 & $\frac{\infty}{\text { 里 }}$ & 总 & 兽 & $=1$ \\
\hline ס्ञ & 으 & 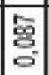 & $\frac{m}{5}$ & $\begin{array}{l}\overline{0} \\
\\
\end{array}$ & 骂 & 果 & 少 & \begin{tabular}{|l|}
$\frac{10}{2}$ \\
\\
\end{tabular} & 要 & 兽 & 은 \\
\hline 핟 & का & : & 윰 & 돟 & 웅 & 爱 & 5 & g & 움 & 18 & \\
\hline & & 0 & $0^{\circ}$ & 0 & 0 & ㅇ & : & 0 & $0^{\circ}$ & 0 & \\
\hline$\frac{\pi}{4}$ & $\infty$ & 옹 & 思 & $\mid$\begin{tabular}{|l}
$\overline{\overline{0}}$ \\
$\overline{6}$ \\
$\overline{0}$
\end{tabular} & $\frac{8}{\frac{8}{5}}$ & 용 & 臬 & 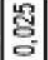 & 号 & 匍 & $\begin{array}{l}5 \\
8 \\
0 \\
0\end{array}$ \\
\hline & r & 多 & 흠 & 영 & 垔 & 형 & $\overline{8}$ & 용 & 8 & 용 & 8 \\
\hline & & 101 & $\sigma^{\prime}$ & o' & ¿l & $0^{\circ}$ & 0 & ' & 0 & 10 & \\
\hline & & 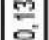 & 总 & 驾 & $\frac{2}{0}$ & 总 & 등 & 总 & 욤. & 音 & 8 \\
\hline & 4 & 莩 & 8 & 등 & 要 & E & 웅 & 18 & 용 & 舆 & 梠 \\
\hline 은 흥 & & - & - & 망 & 0 & 응 & 응 & 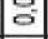 & 영 & 응 & \\
\hline & 7 & $\frac{8}{2}$ & 罗 & 영 & 魚 & 落 & 多 & 옹 & 查 & 8 & $\frac{g}{8}$ \\
\hline & m & 영 & g g & 5 & 贯 & 9 & $\overline{8}$ & 18 & 8 & 8 & 8 \\
\hline & & 0 & $0^{\circ}$ & 0 & - & $0^{\circ}$ & 0 & 0 & $0^{\circ}$ & 0 & \\
\hline 出 & $\infty$ & 5 & 영 & 要 & $\mid \begin{array}{c}\frac{8}{8} \\
\end{array}$ & 产 & 홍 & 홍 & 8̊ & 营 & 8 \\
\hline$\frac{\dot{y}}{\dot{y}}$ & - & 8 & $\frac{10}{5}$ & 융 & 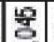 & क् & 영 & $\frac{20}{5}$ & $\overline{8}$ & 竞 & $\stackrel{9}{c}$ \\
\hline 옴 & & 10 & o & 0 & \% & 0 & 0 & 0 & 0 & 0 & \\
\hline 透 & II & & & . & है & 实 & है & . & |ব্র & $\mathbb{S}$ & \\
\hline
\end{tabular}




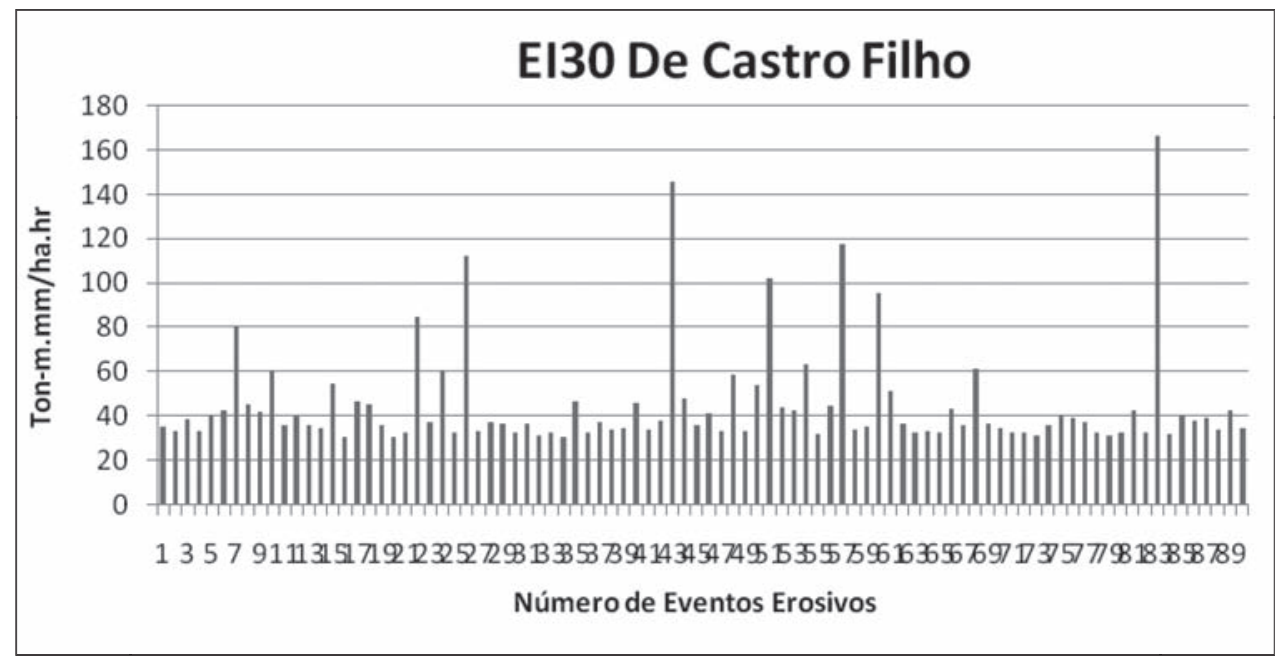

Gráfico 2: índice de Castro Filho para cada uno de los eventos erosivos identificados. Estación: Boca de Pozo. Serial 0791.

En lo que respecta al índice de Lo et al, este coincide con año de mayores precipitaciones y de incidencia de eventos erosivos, por lo que tales variables pudieran estar correlacionadas (Gráfico 3).

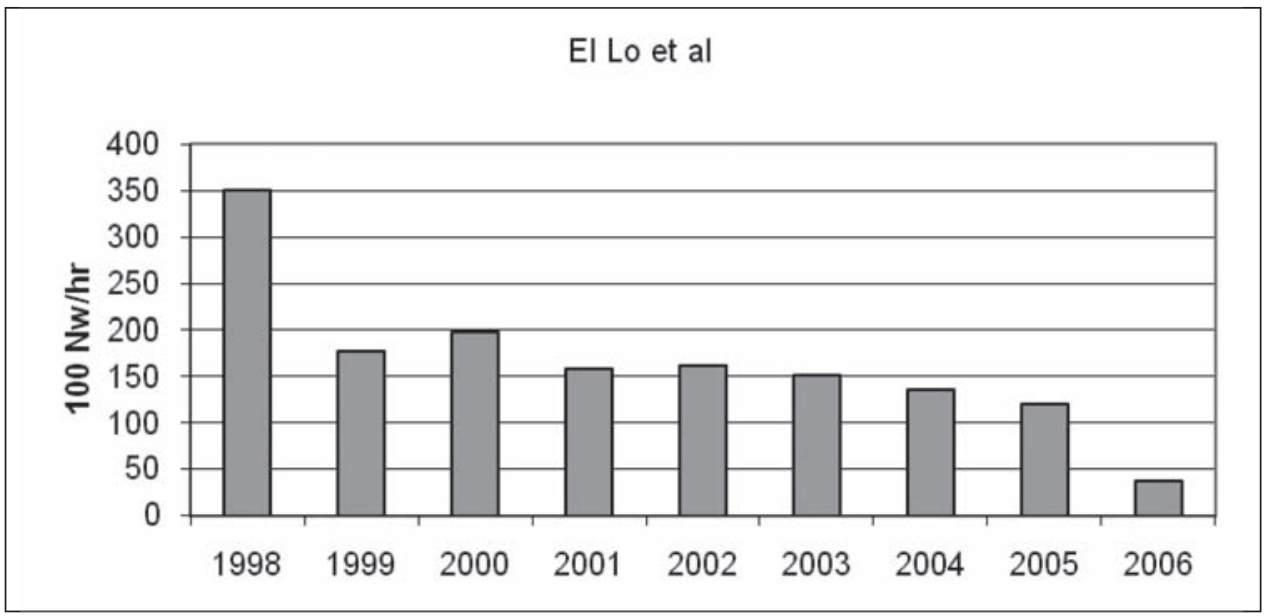

Gráfico 3: índice El Lo et al anual. Estación: Boca de Pozo. Serial 0791. 
De los datos analizados se puede llegar a la conclusión que el año de mayor incidencia de eventos erosivos de acuerdo a los índices de EI de Lo et al y el índice EI30 De Castro Filho es el año de 1998 el cual coincide con el año de mayor cantidad de mm de lluvia y de acuerdo con el índice de EI, la erosividad se presenta con mayor incidencia sobre los meses de julio a septiembre, lo que concuerda con la distribución media horaria de las precipitaciones a lo largo del mes. Estos eventos se presentan en su mayoría los primeros diez días del mes con una frecuencia mayor sobre las horas de 12:00 pm a 9:00 pm y por ultimo, las condiciones del área reflejan que existe una baja protección del suelo, por lo que la susceptibilidad del suelo presente en el área debe ser muy alta a este tipo de eventos erosivos.

\subsubsection{Estación La Guardia. Serial: 1720}

La estación La Guardia cuyo número de serial corresponde al 1720, esta determinada, en relación a su localización astronómica, por las coordenadas 1059`14” Latitud Norte y $64^{\circ} 1^{\prime} 54^{\prime \prime}$ Longitud Este lo que le confiere estar emplazada en el extremo Este del Parque Nacional Laguna La Restinga dentro de la Isla de Margarita (ver figura 3) sobre el cual se alza un paisaje de planicie aluvial cuyas características físicas guardan estrecha relación a las descritas en la estación Boca de Pozo sólo que en el mencionado paisaje, los sedimentes provienen del pie de la Serranía del Cerro Copey. (Ver figura 3).

Como se puede apreciar en el cuadro 5; los valores de precipitación registrados por esta estación, son más bajos que los de la estación Boca de Pozo; y estos poseen un valor promedio de $286.2 \mathrm{~mm}$ distribuidos de forma unimodal durante el transcurso del año, lo que permite, al igual que en la estación Boca de Pozo, diferenciar dos temporadas bien definidas: una seca y de gran variabilidad, conformada por los meses de enero a junio con una proporción de lluvia que apenas alcanza el $21.97 \%$, este comportamiento obedece a la presencia del centro semipermanente de alta presión de las Azores el cual es empujado hacia estas latitudes durante estos meses, predominando así condiciones de masas de aire seco con escasa humedad y nubosidad, vientos Alisios del NE débiles y pocas precipitaciones, tanto en frecuencia como en magnitud. En cambio en el período de lluvias (el cual corresponde a un período transicional según el criterio de Koeppen) comprende los meses de julio a diciembre, con una menor precipitación menor en el mes de octubre, pero sin embargo, durante este período se concentran el $78.02 \%$ de las precipitaciones debido al ingreso en dirección Sur- Norte de la Convergencia Intertropical, acompañada de vientos fuertes con masas de aire cargadas de humedad e inestables con nubes de gran desarrollo vertical que producen precipitaciones cuantiosas e intensas convectivas y orográficas, relacionadas con el ascenso y enfriamiento rápido de masa de aire calientes y húmedas, además de los eventos «Norte» descritos anteriormente en la estación Boca de Pozo y que contribuye a explicar la torrencialidad de las lluvias presentes en esta temporada.

Al observar los datos en el cuadro 5, comparándolos con los resultados arrojados en el cuadro 2, de la estación Boca de Pozo nos encontramos que ambas estaciones presentan una marcada diferenciación estacional de la precipitación, donde la lluvia promedio corresponde a los $332.9 \mathrm{~mm}$, la cual se concentra alrededor del $80 \%$ sobre los meses lluviosos entre junio y diciembre, y el resto de ella en la temporada seca, entre los meses de enero y mayo, manteniendo en consecuencia un régimen de lluvias unimodal, asociado principalmente a la influencia de los factores generales, como la Convergencia Intertropical, los factores orográficos y aquellos cuya génesis sea producto de los eventos «Norte». Los meses representativos de cada temporada, sobre ambas estaciones, son los meses de abril 


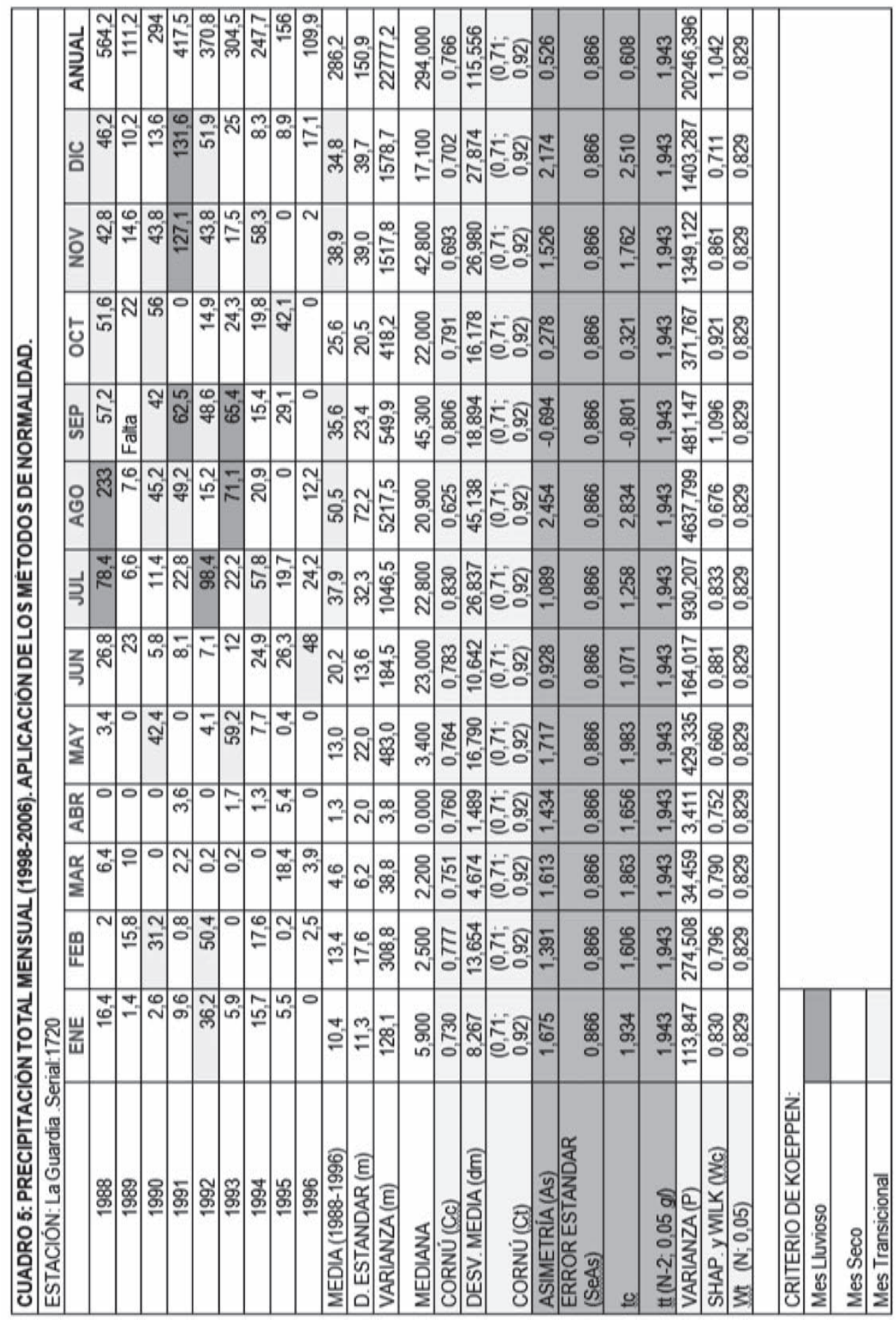




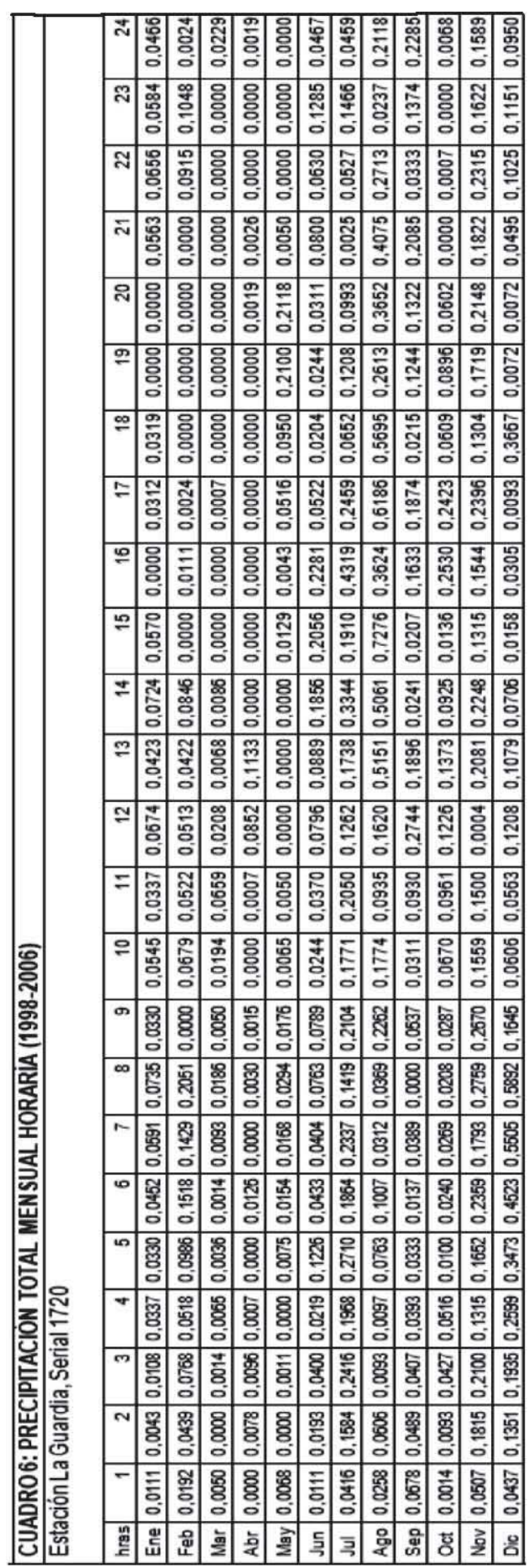

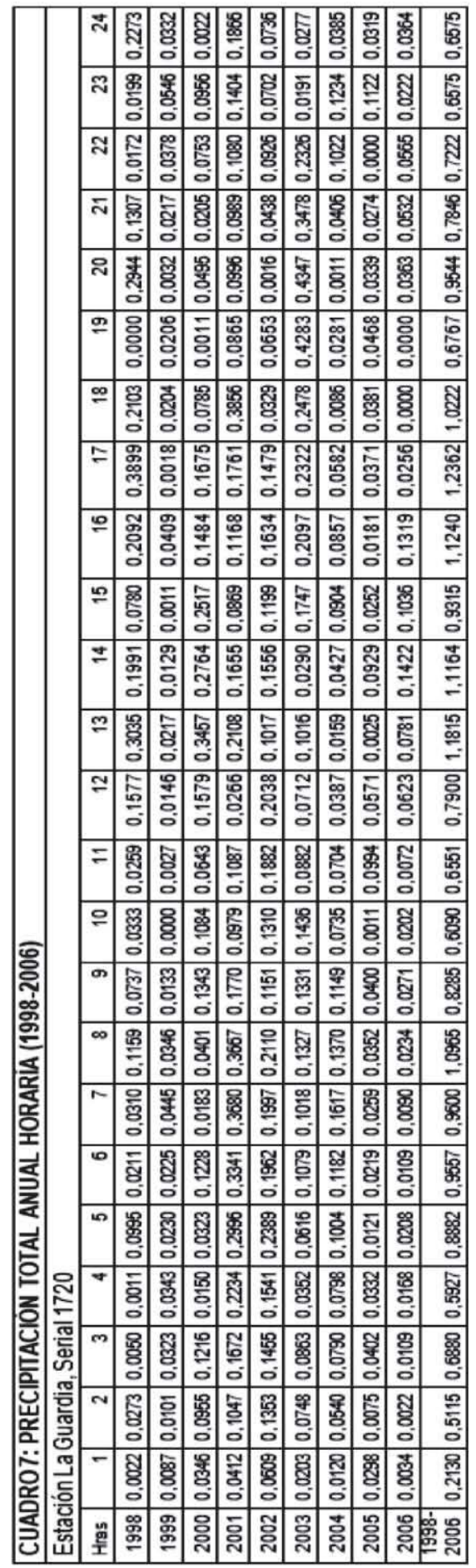




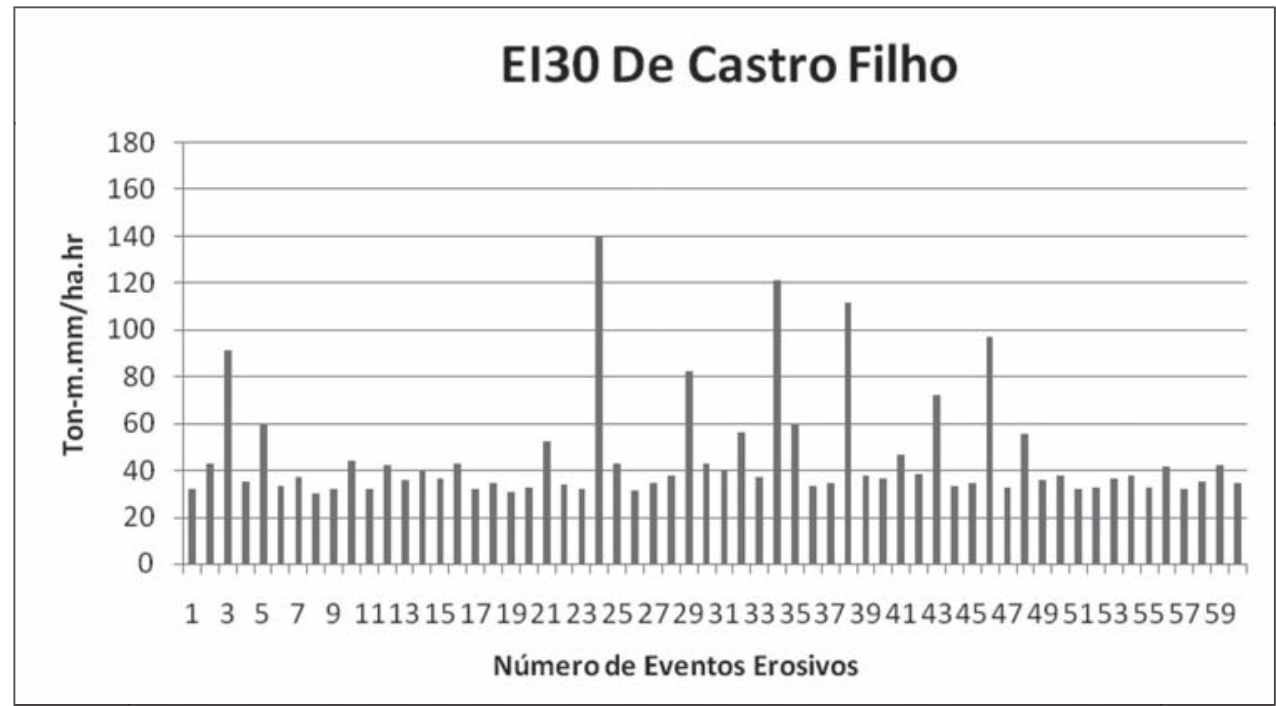

GRÁFICo 4: índice de Castro Filho para cada uno de los eventos erosivos identificados. Estación La Guardia, Serial 1720.

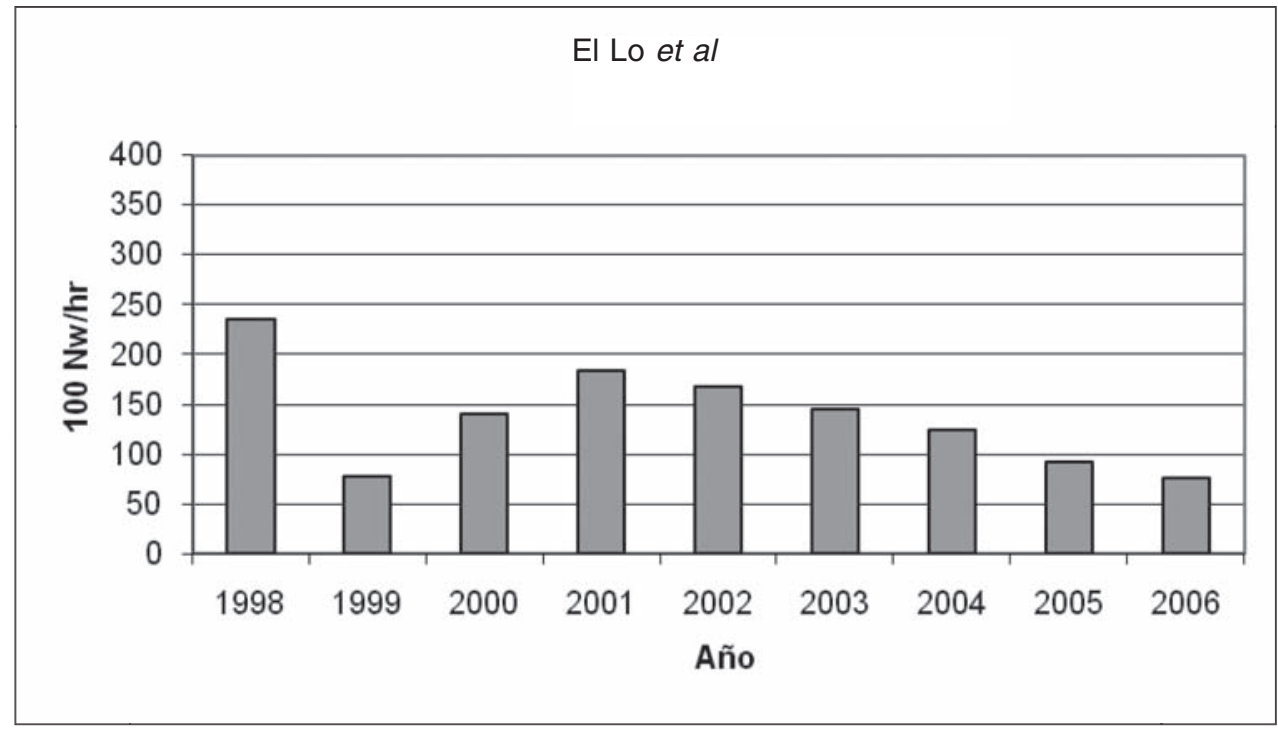

GráfICo 5: índice El Lo Al anual. Estación La Guardia, Serial 1720.

para la temporada seca y agosto para la temporada lluviosa, siendo los años con valores altos y bajos de precipitación los años de 1998 y 2006 respectivamente.

En relación a la distribución de las precipitaciones a lo largo de las horas del día (ver cuadro 6 y 7 para la estación La Guardia), se observa un máximo principal a las 3:00 pm con más de $7 \mathrm{~mm}$ y los valores cercanos entre las 1:00 y 9:00 pm con valores que superan 
los $2 \mathrm{~mm}$. En cuantos a los eventos erosivos, se han contabilizado 60 eventos continuos que superan los $10 \mathrm{~mm}$ los cuales se hayan resumidos en el cuadro 7 reflejan que los mismos se presentaban con una precipitación media de $24.1783 \mathrm{~mm}$ con una desviación estándar de $16.4907 \mathrm{~mm}$ y su intensidad por hora comprendía en promedio los $16.416 \mathrm{~mm} / \mathrm{hr}$, siendo mayor la ocurrencia de los mismos durante las 7:00 pm en los meses de agosto, octubre y noviembre; gracias a estos valores se pudo realizar el calculo de los estadísticos del EI30 De Castro Filho, EI de Lo et al cuyos resultados arrojan la siguiente información.

De acuerdo con el EI30 De Castro Filho los eventos erosivos mas extraordinarios se presentan durante los meses de julio a diciembre coincidiendo con la temporada lluviosa siendo los valores extremos altos y bajos, los eventos ocurridos en julio de 2000 con 139.41 ton-m-mm/ha.hr y el evento ocurrido en agosto de 1998 con 30.40 ton-m-mm/ha.hr respectivamente. A escala anual tenemos que los eventos con mayor cantidad de eventos erosivos se presentan el año de 1998 y coincide con el valor del índice de Lo et al siendo estes $234.8016 * 100 \mathrm{Nw} / \mathrm{hr}$ y presentándose por el contrario los valores más bajos durante el año 2006, debido quizás, por la alta inconsistencia de los datos, referido también en la estación Boca de Pozo.

\section{Conclusiones}

Actualmente ha surgido un aumento de la declinación de la capacidad actual y/o potencial de los suelos, principalmente debido a la erosión, en sus diversas formas y aunque este tema ha sido reemplazado por el problema de la polución, en el ámbito de la conservación del ambiente, esta aptitud o cambio no refleja un caducidad de la importancia de la erosión del suelo en el contexto actual. Sin embargo la falsa noción de ver al suelo como un recurso inagotable ha llevado a observar al suelo como un cuerpo natural no degradable, por lo que las medidas de conservación de los suelos no se llevan a cabo o se ejecutan una vez generalizado el problema de erosión.

Una de los procesos más activos de la degradación de los suelos corresponde a la erosión hídrica y esta envuelve dos secuencias importantes de eventos: El impacto de las gotas de lluvia y su subsiguiente transportación,; por lo que la perdida de suelo será mayor mientras mayor sea la intensidad y duración de la precipitación, pero la misma, puede disminuir mientras se prevenga el impacto de las gotas de lluvia ya sea por medio de la vegetación natural, los cultivos o cualquier otro tipo de cobertura que proteja al suelo.

En lo que respecta a la erosión en América Latina para el año 1954 en los cinco países seleccionados para el estudio (Argentina, Bolivia, Brasil, Chile y Paraguay) existen alrededor de 202 millones de hectáreas de tierras degradadas en los cinco países estudiados y el $46 \%$ de la extensión total de tierras degradadas en los países en conjunto se encuentra afectado por erosión hídrica, $20 \%$ por erosión eólica, $31 \%$ por deterioro químico y $3 \%$ por deterioro físico hay que destacar que en los climas secos favorece la erosión eólica y el deterioro físico mientras que los climas húmedos favorece la erosión hídrica y el deterioro químico.

En lo que respecta al área de estudio seleccionada y las estaciones escogidas para el calculo de los estadísticos referidos a la erosividad, se concluye que, se logró identificar, explicar y diferenciar las características de los eventos erosivos, además que se condujo a representar su estrecha relación con la intensidad y estacionalidad de las precipitaciones en el periodo de 1998-2006 sobre el área en estudio; logrando además hacer análisis que permitió conocer sobre el área, los eventos erosivos se presentan con mayor frecuencia en los meses lluviosos durante las horas de las 1:00 pm a las 9:00 pm presentándose estos con una precipitación promedio de $23.50 \mathrm{~mm}$ y una intensidad por hora de $16.208 \mathrm{~mm} / \mathrm{hr}$ y se 
refleja por ultimo, que los índices De Castro Filho y de Lo et al guardan cierta correlación con la precipitación anual.

Los resultados indican que la erosividad de las lluvias tropicales es producto de pocos eventos con muy altas intensidades y corta duración durante el año, hecho corroborado en los datos de las estaciones Boca de Pozo y La Guardia en la Isla de Margarita y que además confirma los planteamientos realizados por Hudson (1971).

\section{Referencias bibliográficas}

CONSERVATION FOUNDATION \& FAO (1954): Soil erosion survey of Latin America, I, J. Soil Water Conserve. $150 \mathrm{pp}$.

COOKE, R.U. \& J.C. DOORNKAMP (1974): Geomorphology in environmental management. An introduction. Clarendon Press, London. 64 pp.

DE CASTRO FILHO \& BISCAIA, B. (1982): Utilizacao da metodologia de Wilkinson para calculo do potencial erosivo das chuvas em cinco localidades do Paraná. R. Brasil. 25 pp.

DOHRENHELD, R. (1977): Raindrop erosion in the forest. Research Note No 24, Ford Forestry Center, Michigan Technology University. 78 pp.

FREILE, ALFONSO J. (1962): Meteorología y climatología tropical de Venezuela. UCV. 253 pp.

FRENETTE, M. \& JULIEN, Y. (1986): «LAVSED-I -un modèle pour prédire l'érosion des bassins et le transfert de sédiments fins dans les cours d'eau nordiques». Can. J. Civ. Eng., Vol. 13. 15$22 \mathrm{pp}$.

HUDSON, W. (1971): Soil Conservation. Cornell University Press, Ithaca. New York. 15 pp.

WISCHMEIER, W. Y SMITH, D. (1978): Predicting rainfall erosion losses. A guide to conservation planning. USDA. Agric. Handbook No. 537. 211 pp. 